\title{
EVALUATION OF SAPONIFICATION VALUE, IODINE VALUE, PEROXIDE VALUE AND FREE FATTY ACID LEVEL OF ESSENTIAL OIL OF CAYENNE PEPPER (Capsicum annuum)
}

\author{
Aguebor-Ogie Nogiomwan Bobby \\ Department of Medical Biochemistry, SBMS, CMS \\ University of Benin, Benin City, Edo State, Nigeria
}

\author{
Nwosu Favour Ihuoma \\ Department of Medical Biochemistry, SBMS, CMS \\ University of Benin, Benin City, Edo State, Nigeria
}

\author{
Edokhume Peter \\ Department of Medical Biochemistry, SBMS, CMS \\ University of Benin, Benin City, Edo State, Nigeria
}

\begin{abstract}
Cayenne peppers (Capsicum annuum) have been shown to be the world's most cultivated and consumed spice, especially in the temperate and semitemperate regions respectively. It has also been known for its antioxidant, anti-mutagenic and hypocholesterolenic properties as well as it containing essential oil. Here, the total flavonoid and phenol contents and essential oil of the pepper were evaluated for its physiochemical properties which included iodine value, saponification value and free fatty acid value and peroxide value. The essential oil was extracted and the physiochemical properties were analyzed. The essential oil was shown to contain free fatty acid $(0.30 \pm 0.04 \%)$, iodine value $(23.88 \pm 0.23 \%)$, peroxide value $(1.23 \pm 0.02 \%)$ and Saponification value $(141.10 \pm$ $0.35 \%)$. The result indicated that, continued usage of the pepper as a major condiment in preparation of some foods (soups and/or sauces), allows for its medicinal importance to be exploited maximally in relation to health.
\end{abstract}

Keywords-Flavonoid, Phenol, Cayene pepper, essential oil

\section{INTRODUCTION}

Capsicum annuum (C. annuum) is a plant's fruit in the genus, Capsicum, of the family of nightshade, Solanaceae. It has a characteristic pungent odour/scent. It can be cultivated as a value-added processed product, vegetable and spice [1]. It is a common constituent of cooked and/raw food(s). It adds flavour, colour, vitamins (e,g, A and $\mathrm{C}$ ) and a characteristic aroma. It has become indispensable to so many Nigerian chefs, for home use and food industries worldwide [2] as a result of the presence of these nutrients including flavonoids and phenols that are actively involved in promoting health [3]. In other study, it wasreported to have antioxidant, anticancer, analgesic and antipyretic properties $[4,5]$. C. annuum has been shown to be a very rich source of vitamins $\mathrm{A}, \mathrm{C}, \mathrm{B}_{6}$, folic acid and beta-carotene, which is known to provide excellent nutrition for humans [4]. It is being used by security agencies to produce tear gas which is used mostly to control crowds in order to minimize violence [6]. Agronomically, in Egypt, genotypes of various pepper species were found to exhibit differential responses to the Egyptian broomrape which is a chlorophyll-lacking rootparasite and this has led to the use of $C$. annuum as a catch/trap crop to minimize infestation of the parasite [7]. Even though the pepper is very popular in all the agroecological zones of Nigeria and features amongst the most widely used peppers in typical Nigerian dishes, very little has been achieved in the knowledge of its important chemical constituents, nutritional constituents and medicinal benefits to health. Very limited literatures on the phytochemical properties of locally grown cayenne pepper in Nigeria are available. Therefore, this study aimed to examine the physiochemical properties of Cayenne pepper locally grown Nigeria.

\section{MATERIALS AND METHODS}

\section{A. $\quad$ Preparation of plant extract}

Fresh fruits of $C$. апnиum were purchased from a local market (New Benin market) in Benin City, Nigeria and identified at the Plant Biology and Biotechnology Department, Faculty of Life Sciences, University of Benin, Nigeria. They were washed, dried and diced into bits to increase the surface area after which they were oven-dried at $40^{\circ} \mathrm{C}$ until a dry constant weight was obtained and then pulverized. This (250grams of sample) was then subjected to Sohxlet extraction with nhexane for 6 hours. Thereafter, the extract containing the nhexane and the oil were evaporated to separate the n-hexane from the oil. 


\section{International Journal of Engineering Applied Sciences and Technology, 2020 \\ Vol. 5, Issue 2, ISSN No. 2455-2143, Pages 14-16 \\ Published Online June 2020 in IJEAST (http://www.ijeast.com)}

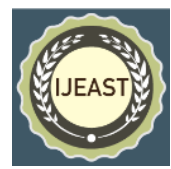

B. DETERMINATION OF FREE FATTY ACID [8]

The free fatty acids is the estimated by titrating it against potassium hydroxide $(\mathrm{KOH})$ using phenolphathalein as indicator. The acid value is $\mathrm{mg} \mathrm{KOH}$ required to neutralize the free fatty acids present in one gram of sample. It is expressed as oleic acid (octadec-9-enoic acid) equivalent. Dissolve $10 \mathrm{~g}$ of oil in $50 \mathrm{ml}$ of the neutral solvent $(25 \mathrm{ml}$ ether plus $25 \mathrm{ml}$ $95 \%$ ethanol and $1 \mathrm{ml}$ phenolphthalein solution neutralized with $0.1 \mathrm{M} \mathrm{KOH}$ ) in $250 \mathrm{ml}$ conical flask. Then added 3-4 drops of phenolphthalein indicator and mixed by shaking. Titrated the content against $0.1 \mathrm{M} \mathrm{KOH}$ until a pink color which persisted for fifteen seconds was obtained.

\section{DETERMINATION OF IODINE VALUE OF OIL [8]}

A $0.001 \mathrm{~kg}$ of oil sample was weighed into a $500 \mathrm{~mL}$ volumetric flask. $15 \mathrm{~mL}$ of carbon tetrachloride was added to the sample and swirled to ensure that the sample is completely dissolved. $25 \mathrm{~mL}$ of Wijs solution was then dispensed into the flask containing the sample using a pipette. The flask was stoppered and swirled to ensure complete mixing. The sample was then placed in the dark for 30 minutes at room temperature. The flask was removed from storage and $20 \mathrm{~mL}$ of $10 \%$ potassium iodide (KI) solution added, followed by $150 \mathrm{~mL}$ of distilled water. The mixture was titrated with $0.1 \mathrm{~N}$ thiosulphate $\left(\mathrm{Na}_{2} \mathrm{~S}_{2} \mathrm{O}_{3}\right)$ solution, adding gradually and with constant and vigorous shaking until the yellow colour had almost disappeared. $1.5 \mathrm{~mL}$ of starch indicator solution was added and the titration was continued until the blue colour disappeared. A blank determination was conducted simultaneously.

\section{SAPONIFICATION VALUE [8]}

A $0.002 \mathrm{~kg}$ of the oil sample was weighed into a volumetric flask. Then $25 \mathrm{~mL}$ of $1.0 \mathrm{~N}$ alcoholic $\mathrm{KOH}$ was pipetted and allowed to drain for about 1 minute into the mixture. A condenser was connected to the flask and the mixture sample was allowed to boil gently but steadily for 45 minutes for complete saponification. The flask and the condenser were then cooled but not sufficiently to form a gel, the inside of the condenser was washed down with about $1 \mathrm{ml}$ of distilled water. The condenser was disconnected and $1 \mathrm{ml}$ of phenolphthalein indicator added. The solution was titrated with $0.5 \mathrm{~N}$ hydrochloric acid $(\mathrm{HCl})$ until the pink colour just disappeared. A blank determination was conducted simultaneously with the sample.

\section{E. PEROXIDE VALUE [8]}

Rancidity is brought about by the action of air (oxidative) or by microorganisms in oil. In oxidative rancidity oxygen is taken by the oil or fat with the formation of peroxides. Peroxide value is a measure of the peroxides contained in the oil. The peroxides present are determined by titration against thiosulphate in the presence of KI using starch as an indicator. Weighed 1 gramof oil into a clean dry boiling tube and added 1 gram of powdered KI and $20 \mathrm{ml}$ of solvent mix. Transferred the tube into boiling water so that the liquid boils vigorously for not more than 30 seconds. Then transferred the contents quickly to a conical flask containing $20 \mathrm{ml} 5 \% \mathrm{KI}$ solution. Washed the tube twice with $25 \mathrm{ml}$ of water each time and collect into the conical flask. Titrated with $0.002 \mathrm{M} \mathrm{Na}{ }_{2} \mathrm{~S}_{2} \mathrm{O}_{3}$ solution to a pale yellow. Further added $0.5 \mathrm{ml}$ of starch, shook vigorously and titrated once more, carefully, till the blue color disappeared.

\section{$F$. Statistical analysis}

Statistical analysis for comparing the data was performed by using IBM SPSS Statistical software, version 20 (IBM Corp, Pakistan). Results are showed as Mean \pm SEM by using the analysis of variance.

\section{RESULT}

The physicochemical properties of oil were determined Table below shows the results from the characterization of the capsicum annuum essential oil. It involves the value of the free fatty acid, iodine value, peroxide value and Saponification value.

Table - 1 Saponification Value, Iodine Value, Peroxide Value and Free Fatty Acid Level of Capsicum annuum

\begin{tabular}{|ccccc|}
\hline Parameter & $\begin{array}{c}\text { Free fatty } \\
\text { acid } \\
(\mathbf{m E q} / \mathbf{L})\end{array}$ & $\begin{array}{c}\text { Iodine } \\
\text { Value } \\
(\mathbf{m g K O H} / \mathbf{g})\end{array}$ & $\begin{array}{c}\text { Peroxide } \\
(\mathbf{m g E q} \\
\mathbf{0} / \mathbf{g})\end{array}$ & $\begin{array}{c}\text { Saponification } \\
(\mathbf{m g K O H} / \mathbf{g})\end{array}$ \\
\hline $\begin{array}{c}\text { Estimated } \\
\text { value }\end{array}$ & $\mathbf{0 . 3 0} \pm \mathbf{0 . 0 5}$ & $\mathbf{2 3 . 8 8} \pm \mathbf{0 . 2 3}$ & $\mathbf{1 . 2 3} \pm \mathbf{0 . 0 2}$ & $\mathbf{1 4 1 . 1 0} \pm \mathbf{0 . 3 5}$ \\
& & & & \\
\hline *Values are expressed as Mean \pm SEM. All analyses were
\end{tabular}
done in triplicate.

\section{DISCUSSION}

Essential oils or "essences" owe their name to their flammability [9]. Essential oils are soluble in alcohol, ether, and fixed oils, but insoluble in water. These volatile oils are generally liquid and colorless at room temperature. They have a characteristic odor, are usually liquid at room temperature and have a density less than unity. Iodine values are often used to determine the amount of unsaturation in fatty acids. In general, higher is the iodine value, higher is the unsaturation and hence higher is the chances of oxidation upon exposure to atmosphere (i.e., rancidity tendency increases). So, it reduces the shelf life of oil. Lower iodine value means they are nondrying and hence their self life is more. Thus, the iodine value 


\section{International Journal of Engineering Applied Sciences and Technology, 2020 \\ Vol. 5, Issue 2, ISSN No. 2455-2143, Pages 14-16 \\ Published Online June 2020 in IJEAST (http://www.ijeast.com)}

obtained in this study classify the Capsicum annum oils as non drying oils which is in corroboration with earlier work by [10]. [11] reported that high saponification values of fats and oils are due to the predominantly high proportion of shorter carbon chain lengths of the fatty acids. Thus, the estimated saponification value in this study which was high, though not up-to the required range accepted in soap industry, revealed that it contains reasonable level of short chain fatty acids and as well, not too suitable for soap industry. Detection of peroxide gives the initial evidence of rancidity in unsaturated fats and oils among other methods that are available, but peroxide value is the most widely used [12]. It gives a measure of the extent to which an oil sample has undergone primary oxidation [14]. The peroxide value from this study show that the oil could be of pharmaceutical value. Free fatty acids are considered as defect in oils/ fats because they are degraded or become rancid. Presence of free fatty acid causes rancidity in oils. Acid value determination is often used as a general indication of the condition and edibility of the oil. This is because an increase in acid value is accompanied by development of objectionable flavours and odours [15]. Acid value is used as an indicator for edibility of oil and suitability for use in the paint industry [15].

\section{CONCLUSION}

The preliminary physiochemical studies carried out on $C$. annuum essential oil revealed the presence of some secondary metabolites and properties. The essential oil was also found to possess some degree of unsaturation. Some of these properties of cayenne pepper are of great health benefits such as reducing pain, reducing risk of cancer, aids in digestion. Besides the strict medicinal application, cayenne pepper essential oil can be used in other industries such as food industry, cosmetic industry and chemical industry.

\section{REFERENCE}

[1] Kumar, S., and Rai, M. (2005) Chile in India. Chile Pepper Institute Newsletter (XXII). (pp 1-3).

[2] Dagnoko, S., Yaro-Diarisso, N., Sanogo, P.N, Adetula, O., Dolo-Nantoume, A., Gamby, T.K., Traore-Thera, A., Katile, S., and Diallo-Ba, D. (2013) Overview of pepper (Capsicum spp.) breeding in West Africa. African Journal of Agricultural Research. Vol 8, No 13 (pp1108-1114).

[3] Ogunlade, I., Alebiosu, A.A, and Osasona, A.I. (2012) Proximate, mineral composition, antioxidant activity and total phenotic content of some pepper varieties. International Journal of Biological and Chemical Sciences. Vol 6 No 8 (pp2221-2227).

[4] Nadeem, M., Muhammad, F., Anjum, M., Khan, A.M.R., Saed, M, Riaz, A. (2011) Antioxidant Potential of Bell Pepper (Capsicum annum L.). Pakistan Journal of Food Science. Vol 21 No 14 (pp 45-51).

[5] Pickersgill, B. (1997) Genetic resources and breeding of Capsicum spp. Euphytica. Vol 96 (pp 129-133).
[6] Smith, C.G. and Stopford, W. (1999) Health hazards of pepper spray. N. C. Med. J. vol 60 No 5 (pp 268-274)

[7] Hershenhorn, J., Goldwasser, Y., Plakhine, D., Herzlinger, G., Golan, S., Russo, R. and Kleifeld, Y. (1996) Role of pepper (Capsicum annuum L) as a trap and catch crop for control of Orobanchea egyptiaca and cernual. Weed Science. Vol 44 (pp 948-951).

[8] A.O.C.S. (1993) Official Methods and Recommended Practices of the American Oil Chemists Society, $4^{\text {th }} \mathrm{Ed}$. Published by the American Oil Chemists Society, 1608, Broadmoor Drive, Champaign, Illionis. (pp 61826-3489)

[9] Kyari, M..Z. (2008) Extraction and Characterization of Seed Oils.International Agrophysics. Vol 22 (pp 139-142).

[10] Nielson, S.S. (1994) Introduction to the chemical analysis of foods. Chapman and Hall, New York. (pp 93-207).

[11] Kirk, R. and Sawyer, R. (1999) Pearson's composition and analysis of foods.9th edition, Addison Wesley longman ltd. England. (pp. 9-29, 608-640).

[12] Dobarganes, M. and Velasco, J. (2002) Analysis of lipid hydroperoxides. European Journal of Lipid Science and Technology. Vol 104 (pp 420-428).

[14] Gbalade, O. and Soremekun, R.O. (1997) Evaluation of quality of Nigerian chillies for pharmaceutical formulations. Journal of Pharmaceutical and Biomedical Analysis. Vol 15 (pp 545-548).

[15] Nwokem, C.O., Agbaji, E.B., Kagbu, J.A. and Ekanem EJ. (2010) Determination of capsaicin content and Pungency Level of Five Different Peppers Grown in Nigeria.New York journal. Vol 3 No 9 (pp 17-21). 